\title{
Clostridium difficile
}

National Cancer Institute

\section{Source}

National Cancer Institute. Clostridium difficile. NCI Thesaurus. Code C76276.

A species of Clostridium that is the most significant cause of pseudomembranous colitis. 